\title{
BEAUTY - TRUTH - GOODNESS; THE COMPLEX AND AMBiguOUS ROLE OF THE MUSEUM
}

\author{
Hans Pedersen
}

The happy cities are those that have an architecture (Le Corbusier 1923)

There is at present a consensus, more pronounced than for a long time, among curators that we are above all professionals, and as such we collect, list, prepare and exhibit a representative range of objects and buildings to document our cultural heritage. We uphold the old ideal that museums impartially provide knowledge to further the enlightenment of the people.

Nevertheless, quite a few among us accept the fact that museums have, and in fact should have, a political role. The era of loud political slogans is gone. However, there is still a strong desire to support some idea or other about community development, albeit in a more modest version than one harking back to the days of the growth of the national state at the turn of the century, or the one reflecting the mobilization of the 70s to strengthen local culture and identity. As a basis for museum work it is nowadays quite legitimate to refer to women's culture, Sami (Lappish) identity and the development of ecological consciousness.

A more salient idea is that advocating that museums ought to be of practical use even beyond the traditional sphere of cultural politics, a notion shared by a growing number of politicians, bureaucrats and curators.

Urban renewal and tourism constitute central examples of areas where museums are expected to act as practical and professionally unbiased contributors.

Among the efforts to make the protection of cultural monuments and the museum service more practically useful, the most recent is the attempt by the Norwegian Ministry of Cultural Affairs to use building preservation as a means of enhancing the aesthetic quality of the built environment and in particular of the public urban space, allegedly in decay. (The initiative may well be regarded as 
132 copying recent similar concern on the part of other Western governments.)

Thus taking the sting out of the cultural-political role of the museums and simultaneously attaching greater importance to their joint responsibility for a vast array of technically defined social tasks raises, as far as I can see, little discussion.

Obviously, a trivial explanation may be that such public assignments provide sorely needed funds. Since the traditional cultural-political interest in the museums has waned, many of them simply appear to be institutions without any proper tasks, with an appurtenant and precarious economy. Local and central authorities appropriating funds cannot be expected endlessly to bend over backwards to pay for "impartial» knowledge provided by sundry museums large and small. To safeguard their existence and potential growth quite a few museums simply have to relate to the changes in the market of public assignments.

To explain the tangible desire to adopt the role of museum technocrats, I think we must point to the fact that people involved in museum work, more than any others, have inherited the notion prevalent among the intelligentsia of the $17 \mathrm{th}$ and 18 th centuries that cultural and social discords can and should be assuaged, and that the museums as managers of history have a particular responsibility in this field.

Whether or not we are aware of it, curators still nurture, to put it portentously, the idea of the rise, fall and potential rebirth of civilization [German: Kultur], a notion that makes us the obvious midwife in various contexts. The basic challenge appears to be to contribute to the restoration of the lost harmony between beauty, truth and goodness.

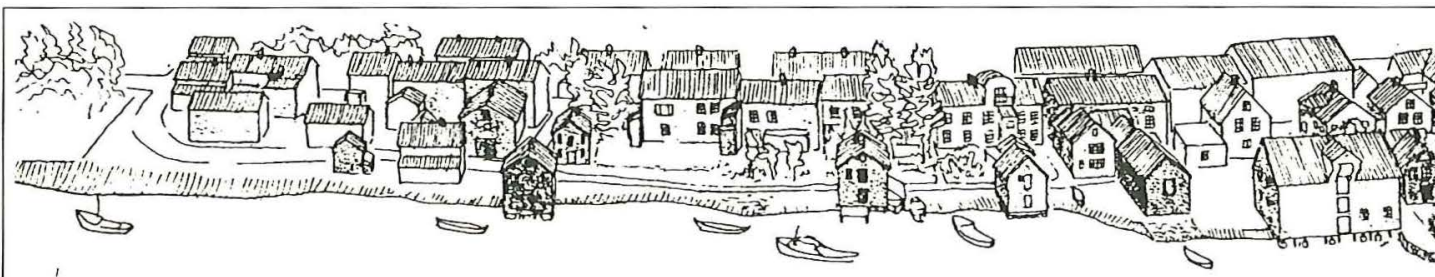

SJØGATA, Mosjøen today

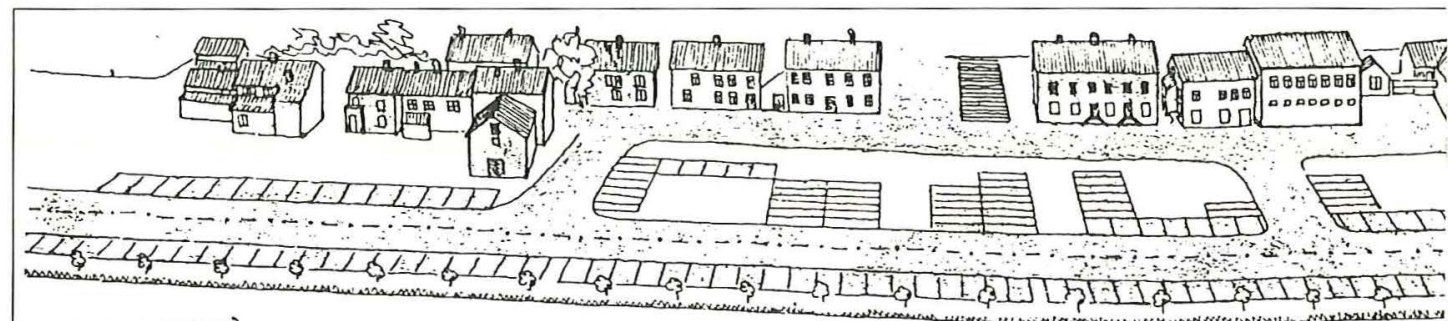

tomorrow? 


\section{PERSONAL EXPERIENCE}

My line of argument is based on personal experience of being involved in museum work and the preservation of buildings in Mosjøen, a small town in northern Norway.

There is no denying the fact that my commitment has mainly been inspired by the radical ideals of the 1970s upholding that the museums should be at the service of the people, i.e., the local community; and that history, instead of being stowed away in the museums' storage spaces, should remain an integral part of people's everyday life. (e.g. the attempt to promote an "ecomuseum" philosophy.)

Moreover, my interest in local culture, identity and regional policy was based on the knowledge absorbed during my studies of social anthropology in Bergen and Tromsø.
On being appointed manager of the local museum in 1980, I consequently enthusiastically plunged into the work of saving and rehabilitating "old Mosjøen", i.e., the Sjøgata area, which at the time was in a deplorable state of decay and facing potential slum clearance.

The work at the open air museum, the original base of the museum, simply had to wait. It constituted, after all, an anachronism, erected on the idea of the peasant as the legitimate manager of the national cultural heritage, a notion dating from the Romantic period.

In many respects the efforts in the Sjøgata area have proved highly successful. The hundred or so buildings in the old part of the town have been declared a preservation area by municipal order. The work has been designated a national pilot project, and has been funded by central authorities. The result has also been awar-
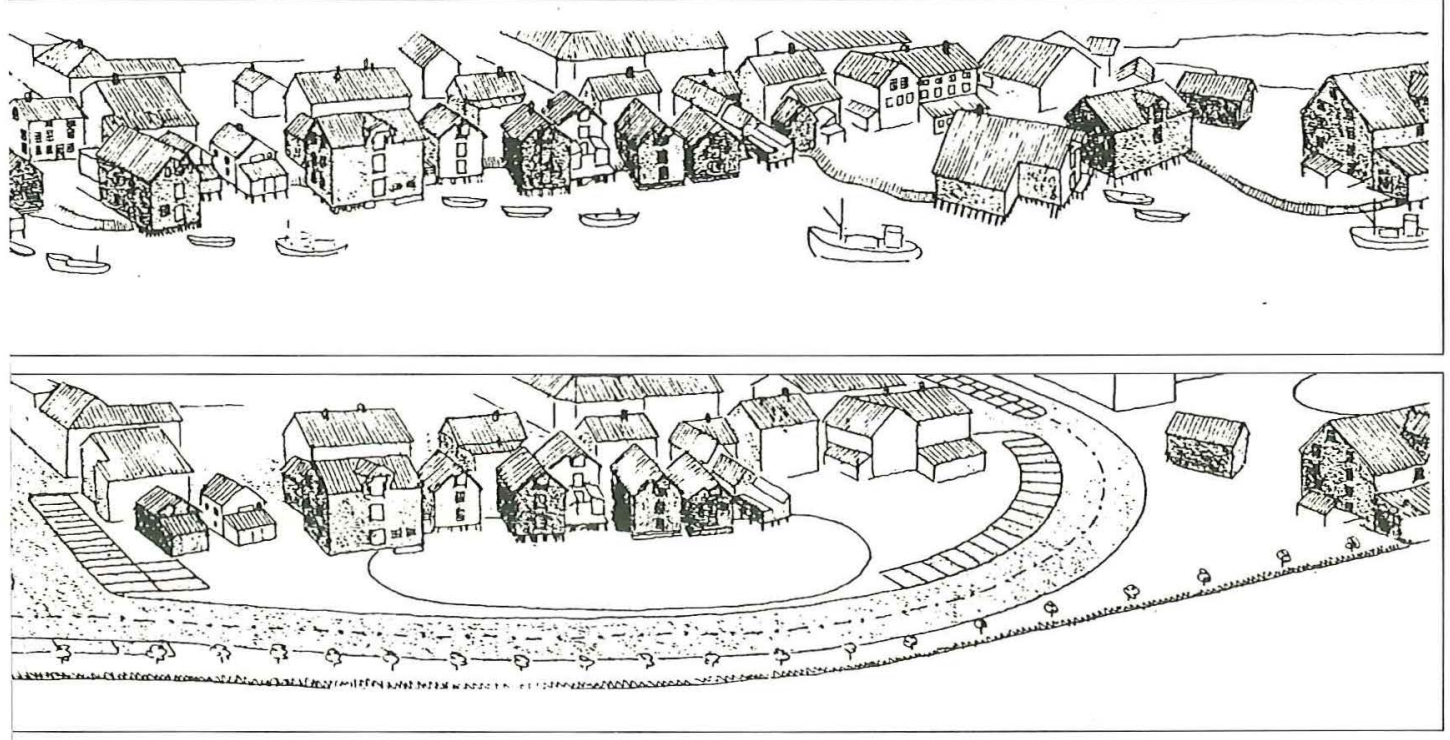
HANS PEDERSEN

134 ded a national architecture prize (The Diploma of the Houen Legacy), and a national environmental prize (The Maihaugen Prize).

In other words, the result is in a way a successful example of what the Ministry of Cultural Affairs had in mind when it promoted the embellishment of public space on a national scale, based on the Norwegian building heritage. Our work in Mosjøen, is also presented as an achievement to be emulated in other ways.

However, if one wishes to be self-critical, one would have no difficulty pointing out numerous unsolved museological dilemmas in the Sjøgata project, which may support a dubious interpretation of history.

For instance, there is solid proof which refutes the assertion that what we like to call "local building tradition" is under all circumstances a suitable basis for the development of local solidarity and community consciousness. Furthermore, more often than not, the architectural quality may well be at variance with that which supports people's sense of identity.

If we are to take the course desired by the ministry of Cultural Affairs, and try to counteract the alleged aesthetic decay in the public space, it is thus of vital importance to realize that the requirements of historical proof, the criteria of building aesthetics and the common sense of local politics are often in opposition to one another.

\section{A BRIEF ACCOUNT OF BUILDING- AND PLANNING HISTORY}

In order to make tangible some of the ways the preservation work in Mosjøen has unintentionally interfered in the local community, it is necessary to sketch briefly the town's history.

The original settlement at the outlet of the river Vefsna consisted of a $400 \mathrm{~m}$ long row of boat sheds erected by the farmers of the valley above. The buildings were made for storing boats and equipment used by the Lofoten fisheries (and other inshore fishing), and were otherwise made use of when attending church or visiting the two local merchants who also owned buildings by the river.

As this settlement was situated on the edge of a large, flat, wooded, and sandy area the possibilities for further growth were naturally present. Mosjøen developed into a small town from the 1870 s onwards after the establishment of a large-scale forestry and sawmill industry in the region: "The North of Europe Land and Mining Company Ltd.», employing about 700 workers.

In this way Mosjøen was one of modern Norway's towns which at a very early stage became an integral part of the emerging international industrial community. For a long time, moreover, Mosjøen was the town in the district of Helgeland. Thus it emerged not only as an industrial town, but also as a rural one, where inland farmers (including Swedes from mountain districts), Sami people and coastal inhabitants came to sell their goods, and to buy an ever-increasing number of handicraft products and mass-produced goods.

The buildings in the Sjøgata preservation area thus form an environment possessing a distinctive character where urban and rural cultures coalesce in a particular way, whereas the adjoining quarters to the east of the preservation area at first sight 


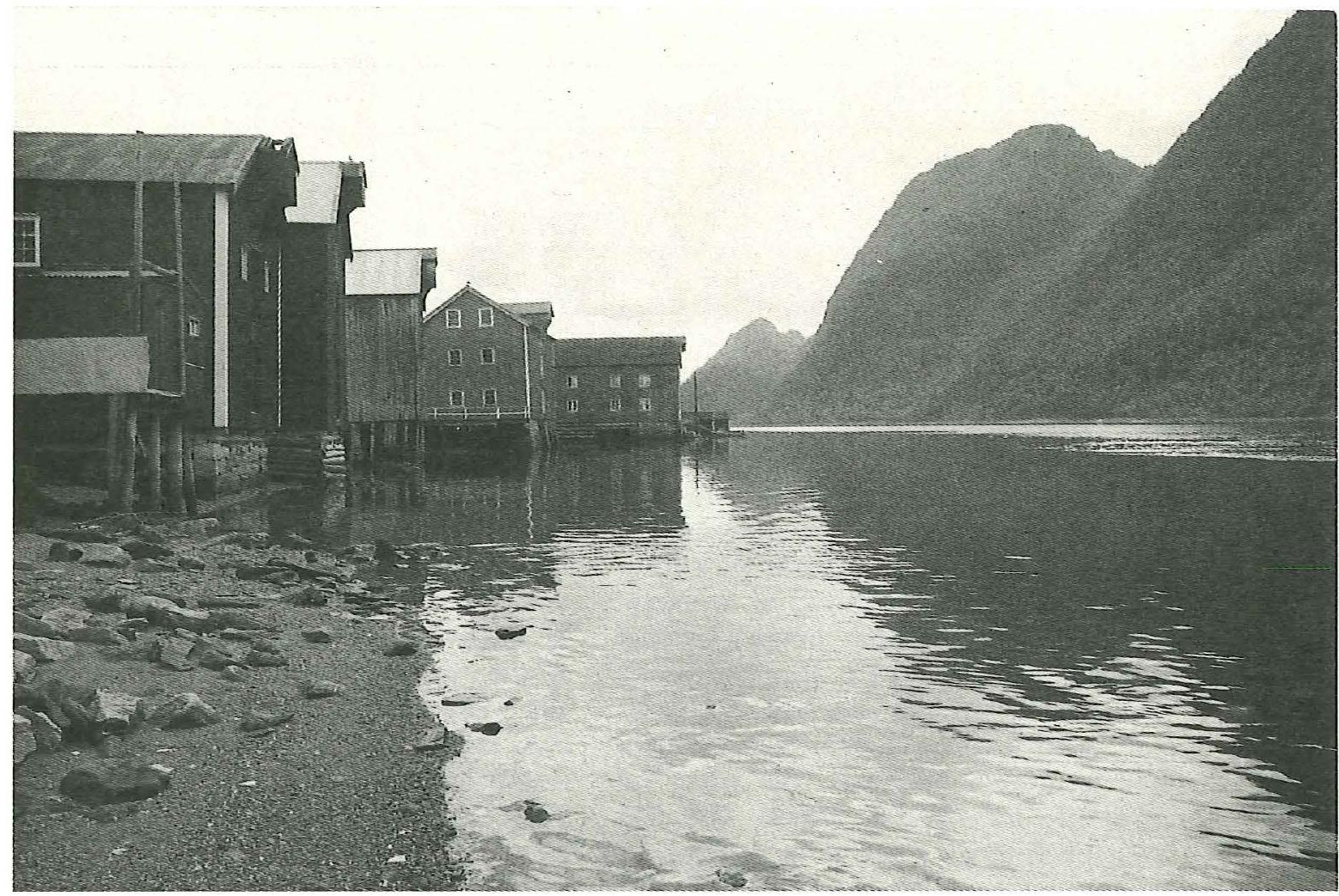

Mosjoen - from the original settlement at the outlet of the River Vefsna; here the seaside of the buildings in "Sjogata".

appear to be the result of a more even growth.

But even in Mosjøen, the built environment is a product of interaction between competing ideologically coloured ideals concerning the good urban life, imported from abroad. The apparently harmonious townscape hides, as will be revealed, various stages of development, which even in retrospect are perceived differently according to social and cultural leanings.

\section{MIDDLE CLASS DILIGENCE AND EQUAL OPPORTUNITIES}

In 1875 Mosjøen became a municipality, and was granted the legal rights of a town, which implied the requirement of a proper town plan. An ordinary gridiron plan as prescribed by the current building regulations was quickly prepared. This was the standard international planning model for the expanding towns of the 19th century, satisfying the need for an orderly urban environment. It was above all regarded as a practical way of arranging the distribution of building sites, making all lots equally accessible. The gridiron plan provided a basic instrument for co-ordinating the interests of the citizens, be it in Chicago or Mosjøen.

Low, homogeneous wooden houses were erected along the building lines, and soon a typical small Norwegian (and, for that matter, Nordic) town emerged, where the inhabitants endeavoured to live up to the bourgeois ideal of prettiness, symbolized by white-painted picket fences and benches. Birches and rowans planted by "The Association for the Embellishment of the Town" lined the streets, enhancing the image of civic virtues.

These efforts produced an urban environment that made visible the notion of the liberal-minded bourgeoisie, that diligence and the allegedly equal opportunities would create a community where a universal culture of the middle classes would 
HANS PEDERSEN

136 hold sway - just given some time.

Who would not wish to turn the clock back to a time when the streets held such aesthetic qualities? However, restoring the kind of community and world view these streets represented may not be to everyone's desire. Among other things, a product of the growth process was an urban proletariat of day workers who had to accommodate themselves as best they could in the old store-houses and boat sheds no longer needed by the farmers who had given up fishing. A lot of these residents in more or less dilapidated shacks by the river learned the bitter lesson that wellbehaved diligence did not automatically afford access to the middle classes.

\section{THE GARDEN CITY}

By the end of World War I, the planning of the Norwegian northern railway line was well under way. Anticipating a new impetus for growth as this line would eventually reach Mosjøen, some of the more far-sighted citizens began to voice the need for a new and more modern town plan. The national authority on

Mosjoen 1914 - one of the many small Norwegian towns which grew up in the second half of the 1800s as a result of industrialisation. The distribution of the building sites was, as we see, arranged according to the standard international planning model: the gridiron plan.

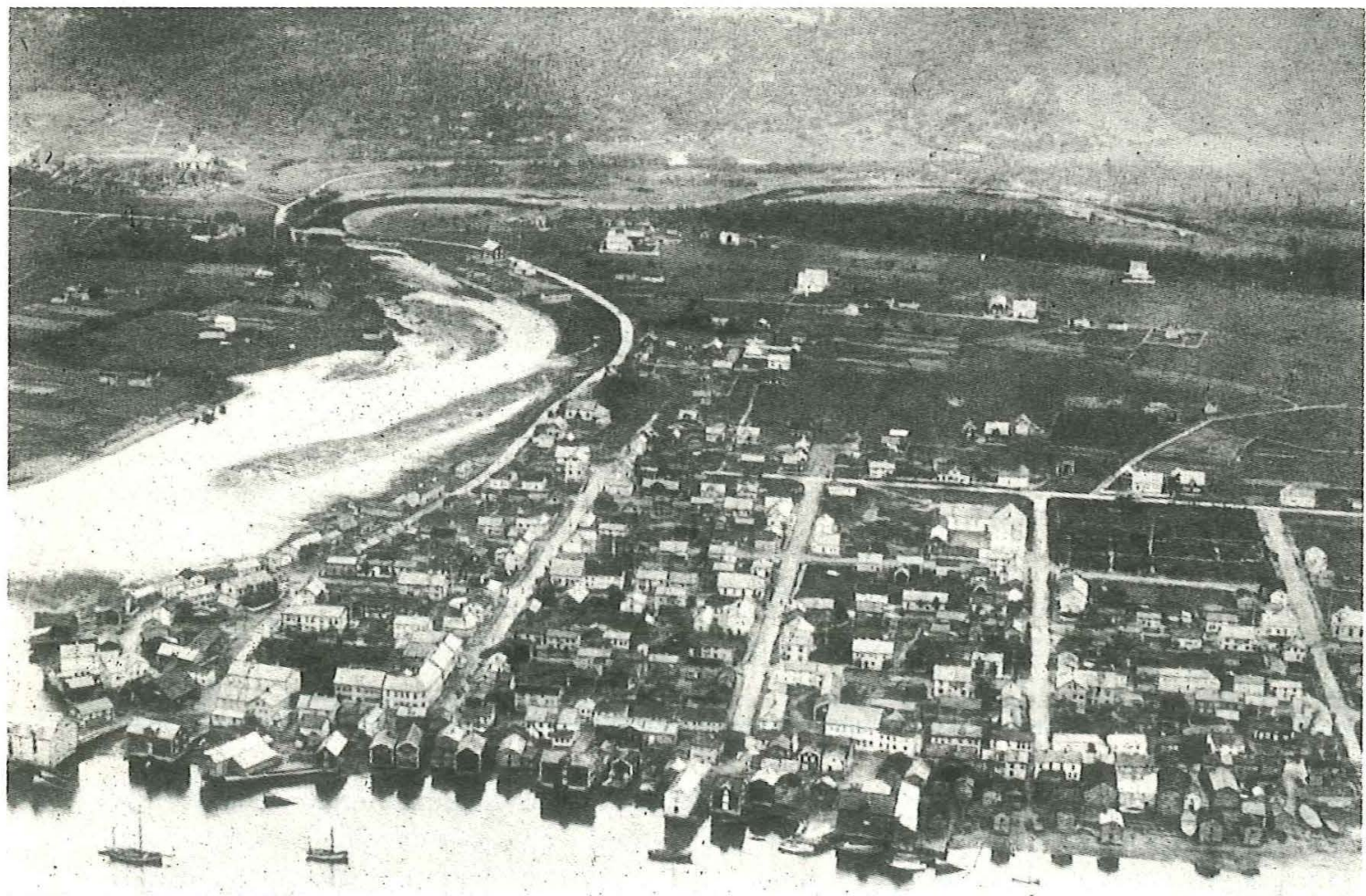




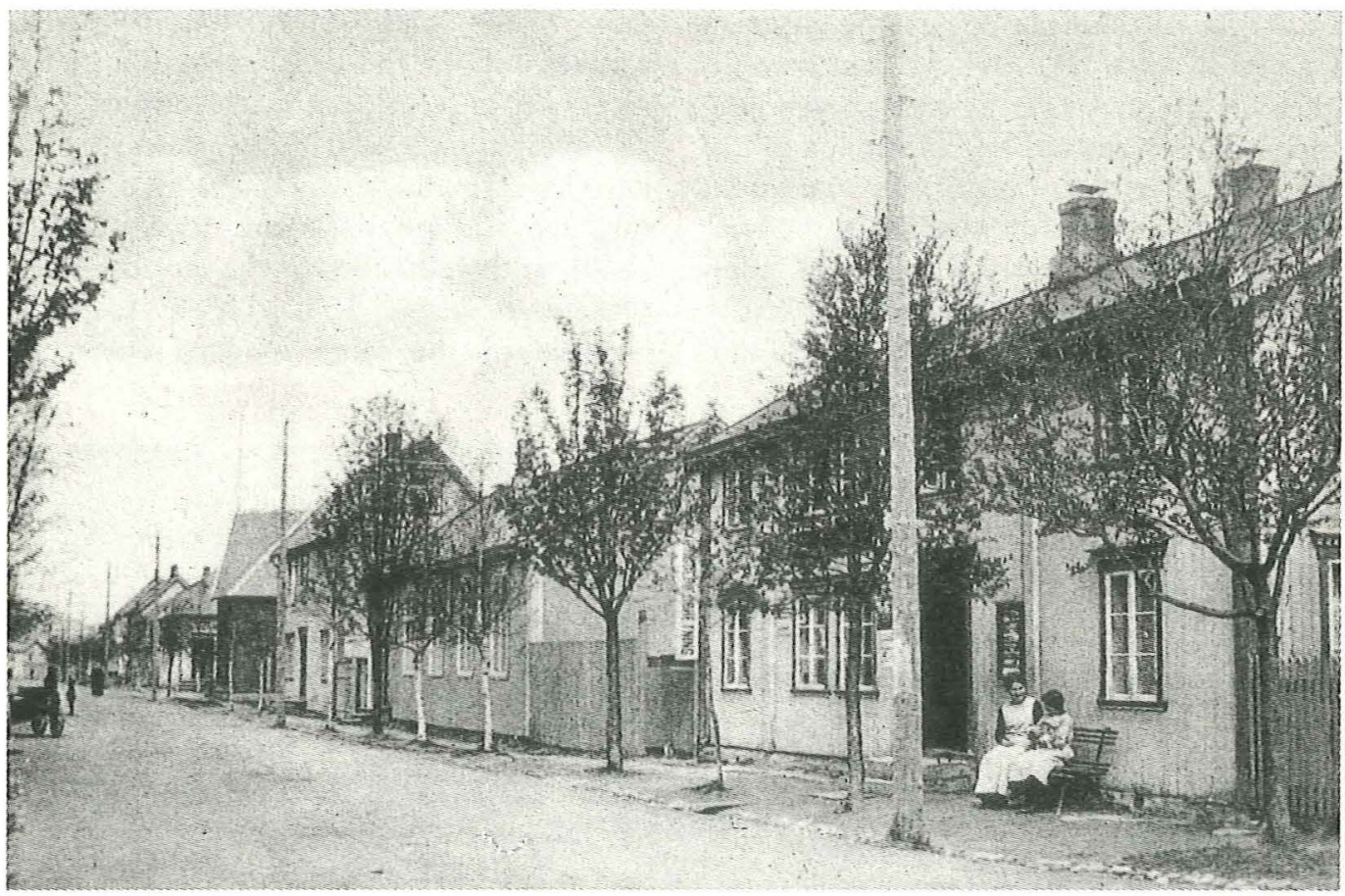

The peasants of the region moving to the town and other immigrants endeavoured to live up to the middle class ideal of prettiness with their homogeneous houses, white-painted picket fences and benches.

town planning of the period, the architect Sverre Pedersen, was engaged to design a plan that could accommodate the expected development. He had recently been installed as the first professor in the field of planning at the Norwegian Institute of Technology in Trondheim.

This concern about planning issues accorded with an international trend. The commonplace and unimaginative gridiron plan had long been criticized for its functional, economic, and aesthetic shortcomings. Theorists and practitioners all over Europe were busy devising new planning methods that could meet the needs and challenges of a modern age. At the turn of the century, a comprehensive con- cept of town planning had evolved, and the new planning ideas were widely discussed also among Norwegian planners, businessmen and politicians.

The new approach to planning stressed the need to consider the actual, unique situation of the town or settlement concerned, and a town plan was ideally conceived of as an instrument for generating desirable development and growth, rather than a mere regulatory measure to avoid the most unpleasant effects of free enterprise. Although rhetorically emphasis was put on functional and social improvement, new aesthetic ideals played an important part.

The widely publicized book on the artis- 
HANS PEDERSEN

138 tic aspect of town design by the Austrian Cammillo Sitte, drawing on careful studies of the public spaces in "self-grown" preindustrial towns, was highly influential. In the US, the "City Beautiful"-movement advocated an aesthetic renewal of the freegrown cities, assuming this would foster "civic pride», and have a morally educational effect on the citizens, besides promo-

ting trade and commercial growth. Concern about the decay of public space is, as we can see, not of recent origin.

Public squares and parks were seen as key elements in a town design that would improve the physical and psychological health and well-being of the city-dwellers. Others, however, had a more sceptical attitude to the large modern cities. In

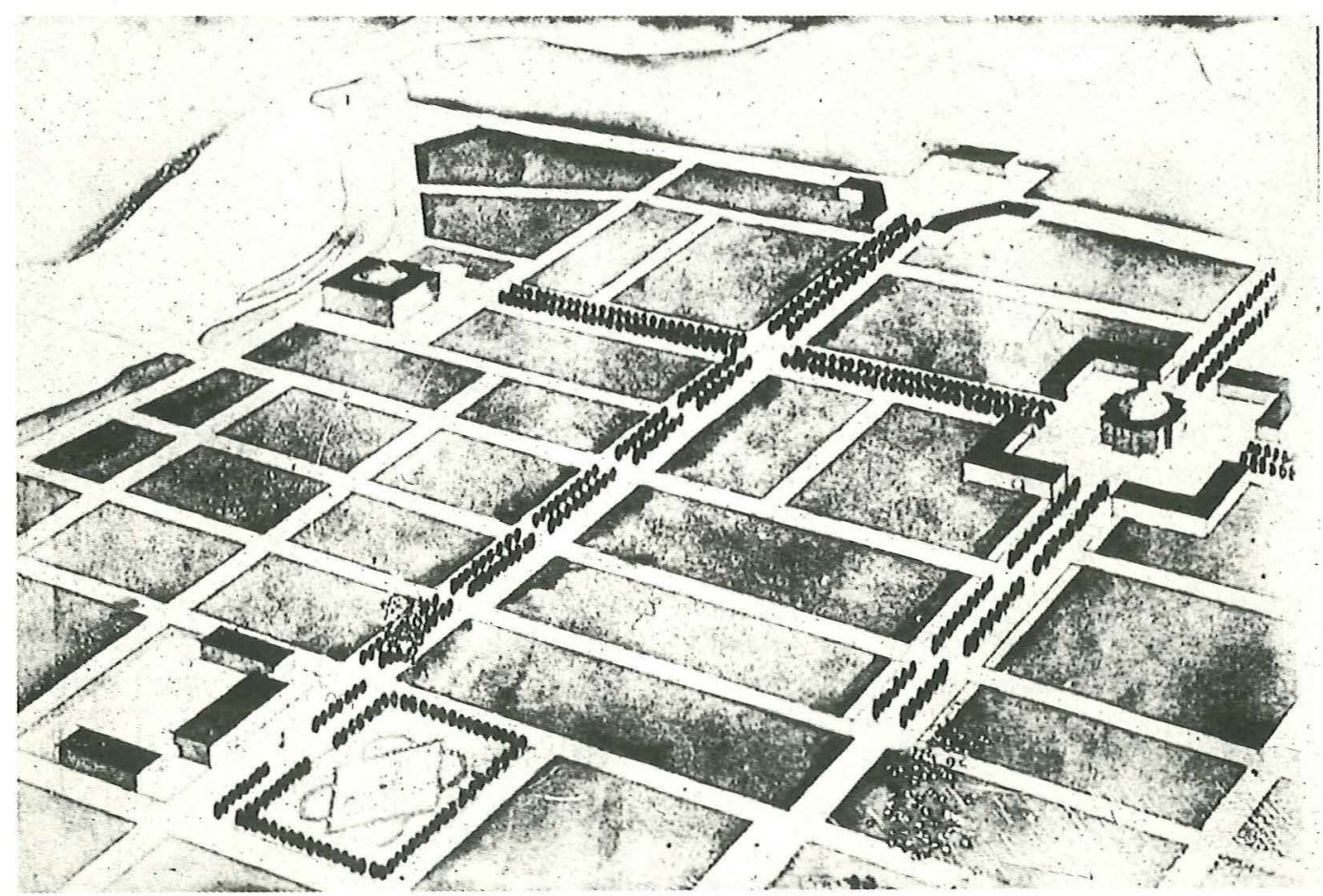

In the inter-war years the national authority on town planning, the architect Sverre Pedersen, was engaged to design a plan that accorded with new international trends. Public squares and parks were seen as important-as well as "The Garden City» ideals. 
The Role of the MUSEUm: BeAuty - TRUth - GOOdNESS

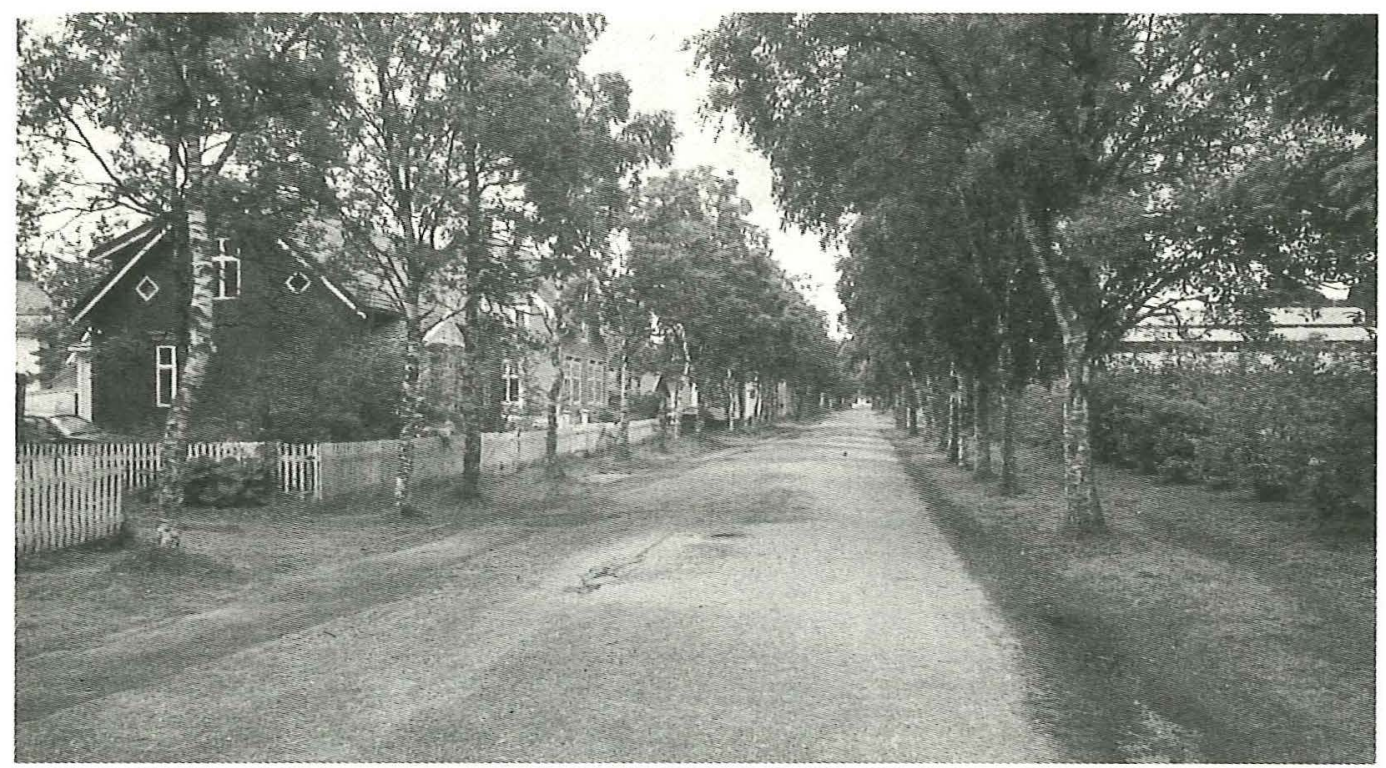

"The Garden City" ideas of "green" urban development soon featured in the town. Here Kirkegata in the 1950s with a sting of "Garden City" in safety.

Britain, Ebenezer Howard proposed an alternative model for urban life, «The Garden City». He regarded the large cities as inherently unhealthy and unfit for human livinge, and advocated instead the formation of small towns surrounded by agricultural land, where everyone could have direct access to a private garden from the ground floor of his small house.

Howard's modest little book, published in 1898, had an enormous impact, and his ideas for a "green" urban development soon became part of the planners' standard repertory.

For a small Norwegian town like Mosjøen, "The Garden City" provided the theoretical frame for a planning that was felt to be in tune with the future, and at the same time appropriate to the special conditions set by available resources, local building traditions, and the Norwegian way of living. In a country where wood was still the most suitable building material, fire safety required ample distances between houses, and wide streets, tree-lined in the manner of avenues, would be conducive to an aesthetically attractive town.

Thus, the implementation of Sverre Pedersen's new plan entailed a transition from the former blocks of uniform size and shape with houses fronting directly on the streets to a garden-city principle characterized by detached wooden houses set in spacious gardens at a distance from the street. The rigid street pattern of the 1875 plan was made more flexible by introducing larger blocks and different street widths, ranging from the more subordinate streets of the dwelling quarters to the broad avenues, serving both as fire inter- 
140 vals and thoroughfares for the new, fast, motorized transport.

Professor Pedersen had a strong preoccupation with landscape, and he was specially concerned about laying out the public spaces - streets, squares and parks - in such a way that experiencing and appreciating the surrounding landscape would be part of the daily life of the inhabitants.

The interest in public urban space was inspired by the neo-classical currents prevalent in the international town planning ideals of the time. The ideal town should be conceived of as a work of art, and private housing should be an unobtrusive, but well-designed element forming a sympathetic background for outstanding public buildings.

The professor even tried to impose design control to ensure that new houses were more in line with the neo-classic taste instead of the then common, popular "Swiss style» idiom of the local builders, with limited success however.

But my main point is that Mosjøen with Professor Sverre Pedersen's plan falls within the larger pattern of town planning history, where the inter-war period evidently was a time when the concern and care for our towns, small or large, boomed. Compared with the periods before and after it may well be argued that the years between the two world wars represent a summit in town planning as a concerted effort to meet both the functional and aesthetic challenges of development.

\section{POST-WAR DECAY}

In the annals of building history, the postwar period is commonly presented as an era of architectural decline. In Mosjøen, one need only think of the brutal way in which large commercial buildings, schools, and blocks of flats were set down among the old wooden houses in the 1950s.

The post-war style of building made the clash between old and new particularly pronounced. Faded functionalism characterized by scarcity of materials and frugality prevailed, and there was little understanding of the demands for architectural quality with regard to size and positioning of the new buildings.

In the early 1960s, however, time and resources became available for the preparation of a new town plan, based this time on the Corbusian version of the garden city. The alleged rigidity of the traditional block plan was to be broken down altogether and buildings freely placed in an open parkland. The planning of a new building for Mosjøen Grammar school offered the municipality an opportunity to create a showcase embodying the functionalist ideals of architecture and planning.

As it turned out, the new grammar school did not quite meet these great expectations. The surroundings could not be changed and the building did not show to its full advantage. Nor did the idea of loosening up the gridiron plan in the central quarters prove feasible, as there was no political will to expropriate private owners.

The result, therefore, was that new buildings emerged here and there in the old block pattern, without any pronounced attempts to establish a coherent vision of the new townscape. To top it all, a majority of the new buildings of the $60 \mathrm{~s}$ and $70 \mathrm{~s}$ embodied what might be called construction engineers' third or fourth rate versions of the architectural ideals of functionalism. 
The decline was, as is evident, a reality! The public spirit and communal will to form had obviously given in to individual busywork and mass-produced eyesores. The local authorities were reduced to being passive organizers, and their contribution confined to the inspection of construction details and the formalities of building and planning regulations.

At any rate, such was the verdict passed by the preservation movement emerging in the 1970s. But may it be that this view, generally adopted by the present official preservation philosophy, was actually based more on aesthetic prejudice and a warped sense of reality than on a will to understand our recent past by providing a more subtle interpretation of the complex economic, social and cultural forces at work.

If we try instead to view the scene as perceived by the local Social Democrats of the time, reality would obviously take on a somewhat different appearance.

To them the architectural discords cha-

Sjogata 1975. Slum clearance - or a preservation area? The question resulted in perhaps the most heated dispute in local politics in Mosjoen after World War II.

Blocks of flats in Radhusgata built in the 1950s. Faded functionalism characterized by post-war scarcity of materials and frugality. A clash between old and new-but does it represent architectural and social decline?
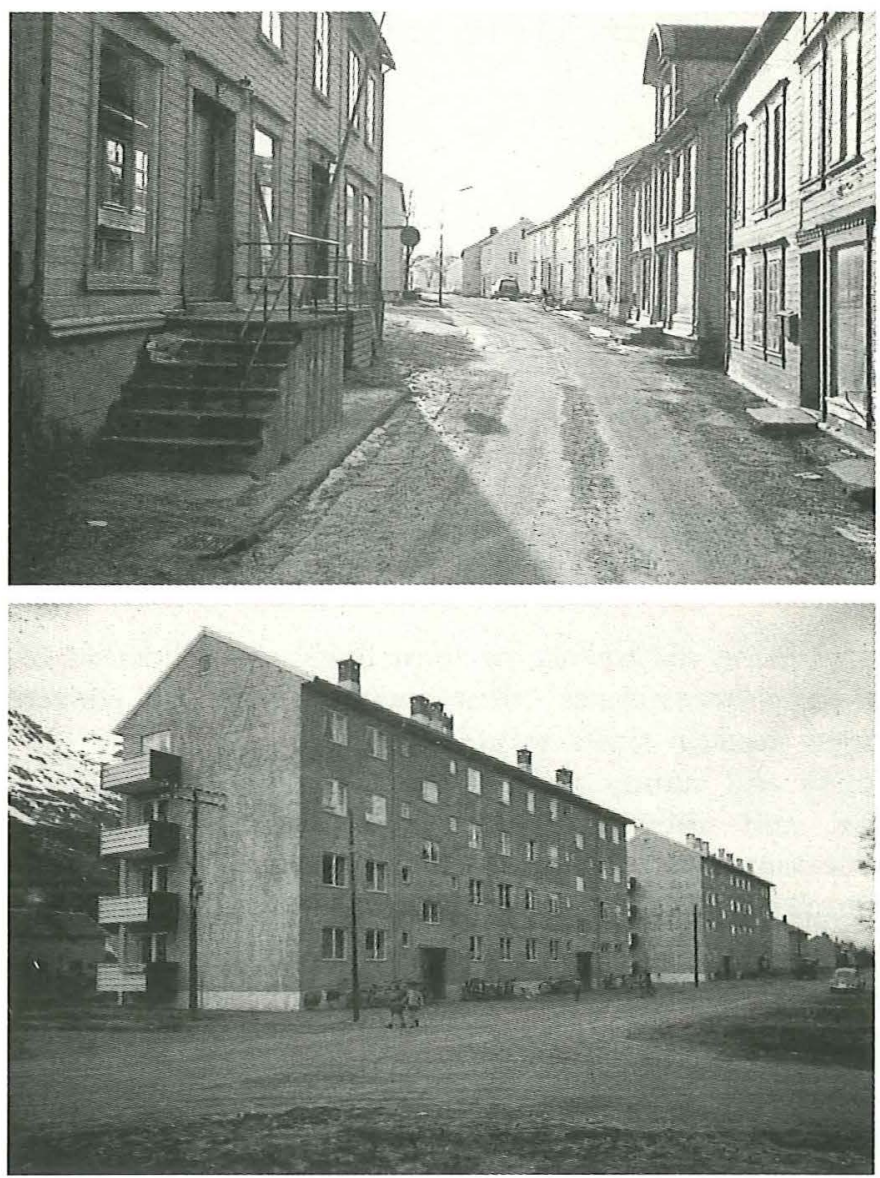
HANS PEDERSEN

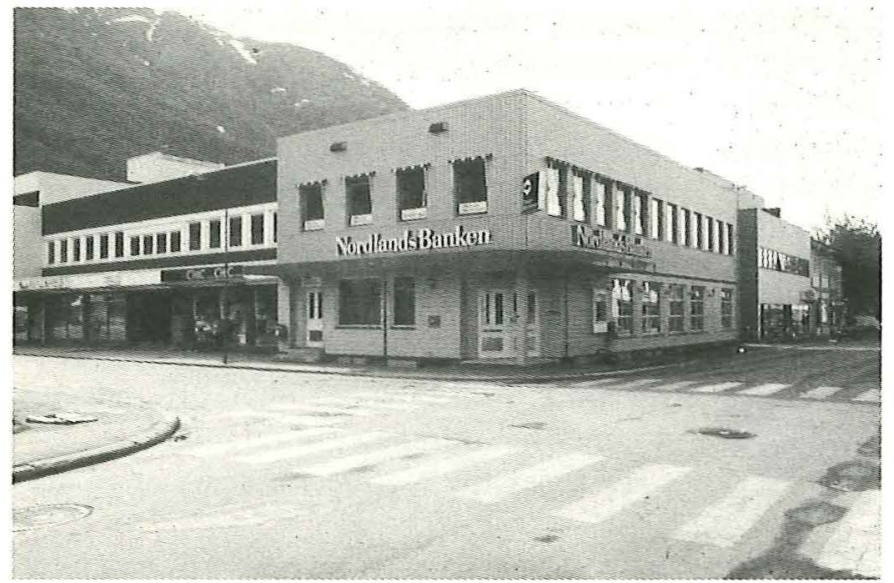

Commercial buildings representative of the architecture of the 60 s and 70 s. Construction engineers' third or fourth rate versions of the architectural ideals of functionalism.

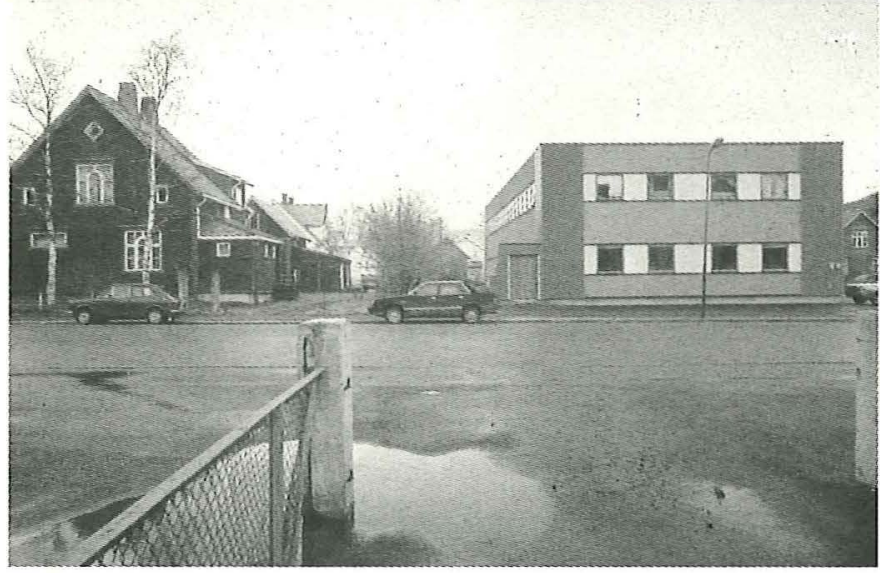

A veritable clash between the vanishing Mosjoen and the modern metal sheeted Mosjoen of the 70 s.

racterizing the townscape most likely seemed a transitional phenomenon. Very soon modern times would conquer every nook and cranny and produce a functional and above all more just society. Functionalism, then, was not evaluated in terms of classic aesthetic ideals, but was an important symbol of the emerging good society, as opposed to the unfair class society masquerading in sundry elegant styles.

Thus, it is obvious that the views of reality prevalent among people involved in museum work often serve as political pleas instead of constituting an unbiased general education.

\section{THE ALLIANCE OF PRESERVATION}

Bearing this in mind it is easier to understand the support of - and resistance to the work to preserve "old Mosjøen".

When the debate about preservation became a topical issue around 1970, the Sjøgata area was clearly in serious decay both in terms of buildings and socially. In addition to a nucleus of «indigenous peo- 
ple» who stuck it out, several alcoholics and other clients of the social services squatted in the area. In the established opinion slum clearance was long overdue.

What gave rise to the preservation movement was, typically of the period, the launching of a planning proposal calling for most of the built-up area to be demolished in order to provide parking space primarily benefiting the department store Domus (of which the Labour mayor happened to be manager).

The proposal provoked the establishment of an alliance between nostalgic citizens, promoters of Norwegian heritage, people hailing from the area and young intellectuals (like myself).

The Sjøgata area, like other similar areas, symbolized a common alternative to the emerging society, which for various reasons was intensely disliked by the preservation enthusiast. The area was a symbol of the social and cultural qualities that many people saw were vanishing in Mosjøen - whereas new planning principles and metal sheeted buildings embodied the deplorable spirit of the time.

What was at the outset the least important to the preservationists, perhaps, was any concern to preserve subtle aesthetic and antiquarian values. That came later.

The opposition to the planning proposal initially resulted in a heated dispute at the local level where feelings ran high, and it raged backwards and forwards for 6 years, Finally the position of the ardent supporters of preservation prevailed. The Norwegian Cultural Council then granted 3 million $\mathrm{NKr}$ for the renewal of the area - thus enticing a number of local politicians finally to dare to join the alliance of preservation.
Against many odds Sjøgata was in this manner turned into a preservation area in 1976 , based on a scheme worked out at the Division of Architectural History at the Norwegian Institute of Technology (NTH) in Trondheim, another ally typical of the period.

\section{THE PHOENIX BIRD}

With the formal decision to save the Sjøgata area, financial support from the Norwegian Cultural Council along with the expertise of the Division of Architectural History at NTH and the Central Office of Historic Monuments recapturing the old Sjøgata ambience should have been easy. And, in truth, gradually houses marked by front wear as well as other obvious signs of decay were replaced by what was overall an attractive and picturesque environment.

Like a Phoenix the Sjøgata area arose to its former splendour - and revealed - pure idyll?

However, behind what is generally agreed is an attractive result there is an ongoing debate about professional, aesthetic, financial and functional values. The agreement to conserve is not, in fact, tantamount to a consensus about what should and could be done in a preservation area.

It is a well-known fact that the advice given by experts is not always accepted at face value by the general public. We have seen that even residents of the Sjøgata area are infected by functionalism and want "uncritically» to adapt their houses to modern functions and standards of comfort. People are sadly apt to look upon the buildings in the area as, well, historical symbols that can easily be adapted for any 
144 purpose whatever, and not as historical documents which ought to remain as unaltered as possible.

Consequently, this cultural clash has brought about interminable quarrels about the disposition of plans, the number and position of windows and the shape and size of extensions. The most radical remodelling proposals have been weeded out by the means of the power invested in the administration of the funds from the Norwegian Cultural Council.

However, on reflection there is a nagging doubt whether our directions have always been solely dictated by legitimate professional considerations. In would be hard to deny that our proposed solutions may have been inspired by the romantic predilection for the aesthetics of decay. Perhaps several of the demands for «functional" changes made by folksy house owners were just as legitimate. Even as local curators we risk being socialized into a professional subculture dominated by elitist norms and values, something which may blind us to the inherent value of the ways other subcultures manage the building heritage.

\section{A PRODUCT AIMED AT TOURISM}

We have of course not been able to inspect every aspect of the preservation work. The popular tendency to overdo things has thus not been halted; in addition, the greenery in particular will occupy a disproportionate amount of the outdoor space.

Making a perfect idyll out of the Sjøgata area obviously presents a phoney historical picture - and jeopardizes the area's value as a means of imparting cultural-historical knowledge. We face the risk of ending up in the same situation as the well-trimmed open air museums which present a fairytale version of our old peasant culture.

The biggest paradox, however, is that the overly idyllic result of the rehabilitation has contributed to removing the final remnants of opposition among the Social Democratic establishment to the preservation of the Sjøgata area.

At the outset they pointedly accused preservationists like us of promoting a romanticized version of the original Sjøgata environment as opposed to the historical reality they considered themselves to be managers of. And even if they have been proved right in a way, they now sing a different tune, because they have realized the potential inherent in the nostalgic version in terms of tourism.

As the local Social Democratic authorities now realize that they may benefit from the Sjøgata area, not in terms of strengthening their identity, but as a local source of income, they are now not only willing to endure the area being dominated by other cultures and world views than their own, they actually contribute financial support for the additional renewal in order to make Sjøgata even more palatable to tourists looking for cosy, «old» environments.

Admittedly, such an effort to attract tourists provides professionals like us with more money to impart cultural-historical knowledge in a suitable way by arranging exhibitions and putting up information signs. Whereas the residents and users of the area must needs put up with being the object of ever-increasing tourist attention - with all the assumed hospitality and sundry drawbacks involved. 


\section{THE AMBIGUITIES OF HISTORY}

This litany of unintended events and dilemmas in which the Sjøgata project is trapped could easily be prolonged, however, considerations of space prevent me from pursuing the matter any further.

Still, I hope that the historical outline will suffice to elucidate a few general challenges facing a majority of museum professionals, challenges we undoubtedly pay far too little attention to in our daily work.
It is thus an obvious challenge to focus on how we deal with the numerous dilemmas involved in combining our professional activity with our roles as politicians and bureaucrats. As far as I can see there is currently little enthusiasm for critical reflection concerning our work as cultural bureaucrats. The fact that most established forms of cultural-political rhetoric have been brought into disrepute, has driven an increasing number to resort to a multifarious activity as experts within the sphere of publicly-paid general practice.

Like a Phoenix the Sjogata area rose to its former splendour?

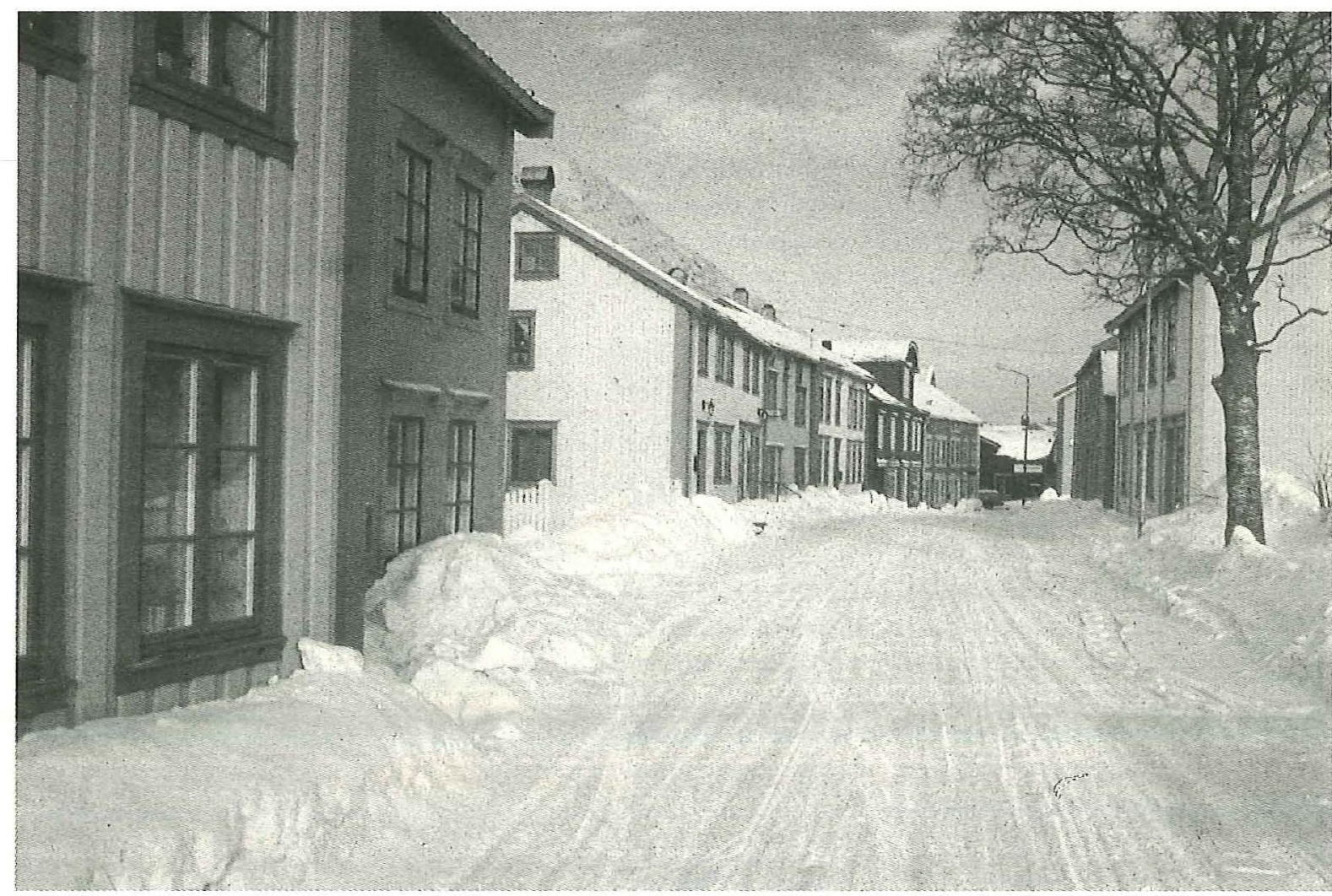


146 The tension between the demand for impartial documentation and the desire to participate in work of social importance is not released by exchanging the Utopian ideals for public assignments big and small.

At all events, we cannot escape the fact that it is impossible to capture reality, be it past or present, in one picture. Expert knowledge as well as Utopian ideas, therefore, more often than not represent very simplistic models of a complex, ambiguous and incalculable whole.

For this reason it is a crucial challenge for the museums to train people's ability to come to terms with the discords and ambiguities of modern society. Instead of allowing the museums to reinforce a nostalgic yearning for a new, fictitious, harmonious golden age, we should dedicate our efforts to alerting people to the opportunities a complex reality provides in terms of moulding the world in their own image, without making concessions to either fundamentalism or post-modern nihilism.

A sharpened awareness of a plurality of perspectives means, among other things, that beauty, truth and goodness emerge as independent and equal dimensions representing a necessary corrective to our deeprooted propensity to aestheticize history.

It may seem doubly ironical that it is, in fact, tourism, which currently provides us with the resources to illustrate Mosjøen's recent history in a more reflective way. Tourists allegedly prefer staged folklore, i.e., mock historical innocence to genuine folkways containing all the ambiguities and discords involved.

But perhaps this may not be the case. We all visit museums primarily during our summer holidays. This is a time of surplus energy and an open-hearted attitude which inspires critical reflection. Given the choice, then, in may not be all that obvious that we prefer historical escapism. The unilateral picture of the tourist as a featherbrained consumer may well be a part of the self-righteous sense of reality found among the intelligentsia.

\section{NOTE}

The argument in this article is developed in dialogue with Dag Nilsen, the architect of the Sjøgata project, with whom for years I have had the pleasure to collaborate. A first version of this article was delivered as a paper at the conference 'The Museum Mission' at the Department of Museology, Umeå University in April 1994.

All photos: Vefsn Museum, Mosjøen

Hans Pedersen is Mag. Art. in Social Anthropology (University of Tromso). From 1980 curator and director of Vefsn Museum, Mosjoen in Norway. Periodically member of the university community (in Tromso and Bergen) as assistant curator, research scholar and office manager. A lasting social and political engagement in different fields and levels.

Adr: Sjogata 45B, N-8650 Mosjoen,

Fax $+47-75172001$ 